\title{
Microstructure evolution of P92 steel weld metal after service for $8000 \mathrm{~h}$
}

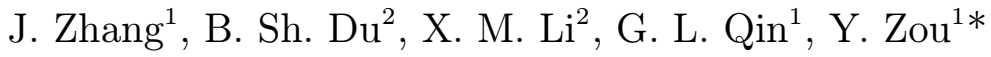 \\ ${ }^{1}$ Key Laboratory of Liquid Structure and Heredity of Materials, Ministry of Education, Shandong University, \\ Jingshi road 17923, Jinan 250061, P. R. China \\ ${ }^{2}$ State Grid Shandong Electric Power Research Institute, Wangyue road 2000, Jinan 250002, P. R. China
}

Received 16 January 2016, received in revised form 5 April 2016, accepted 5 April 2016

\begin{abstract}
Microstructure characterization and impact toughness test were performed on the P92 steel weld metal which was sectioned from the component of the main steam pipe of an ultrasupercritical unit after $8000 \mathrm{~h}$ exposure at high temperature. Precipitates of $\mathrm{M}_{23} \mathrm{C}_{6}, \mathrm{MX}$, and Laves phase were detected in the weld metal. The weld metal after long-term service possessed much lower impact toughness compared with the as-fabricated weld metal. Micro-cracks were also found in the weld metal which formed during the welding process. Impact toughness reduction in the weld metal was correlated with the microstructure evolution.
\end{abstract}

K e y w o r d s: P92 steel, weld metal, microstructure, impact toughness, precipitates

\section{Introduction}

Demands on thermal efficiency increase in power plant have been driving the development of ferritic and austenitic creep-resistant steels [1-4]. The superior combination of high creep resistance, high oxidation resistance, and lower thermal expansion coefficient makes P92 steel become the candidate material for thick wall components in power plants. It has generally been used as the main steam pipe in the ultrasupercritical units.

Owing to the inhomogeneous microstructure and mechanical integrity, most of the failures in components in power plant occur at weld joints. One problem that causes the premature failure of $\mathrm{P} 92$ steel is the type IV failure. For this mode of failure, the weld joint fractured at the fine-grained heat affected zone where the peak temperature reaches around $A_{\mathrm{c} 3}$ during the welding thermal cycle $[5,6]$. Another concern with regard to the failure of $\mathrm{P} 92$ steel weld joint is the weld metal which is often characterized by a dramatic reduction in fracture toughness.

The lack of experimental data regarding microstructure and properties of weld metal which are obtained from the P92 component under service condi- tion makes this type of investigation novel and vital. In this study, the microstructure and impact toughness of the P92 steel weld metal after long-term exposure at high temperature were analysed systematically. It is expected that this study can be used to harness the understanding of the correlation between microstructure and properties of weld metal of P92 steel under service condition and extend this to inspection and control of degradation of boiler component containing P92 weld metal.

\section{Experimental procedure}

The experimental material was sectioned from weld joint of a thick wall P92 main steam pipe with dimensions of $\varnothing 370 \mathrm{~mm} \times 60 \mathrm{~mm}$ in a commercial ultrasupercritical unit that had been operating for $8000 \mathrm{~h}$ at $605^{\circ} \mathrm{C}$. The chemical composition of the weld metal and the P92 steel is shown in Table 1. For the welding procedure, a combination of TIG and SMAW with weaving has been adopted, followed by a post welding heat treatment. Detailed welding parameters and the heat treatment curve can be found in Table 2 and Fig. 1, respectively. For comparison purpose, a new

*Corresponding author: tel: +86-531-88399872; e-mail address: yzou@sdu.edu.cn 
Table 1. Chemical composition of P92 steel and its weld metal (wt.\%)

\begin{tabular}{lccccccccccccccc}
\hline Materials & $\mathrm{C}$ & $\mathrm{Si}$ & $\mathrm{Mn}$ & $\mathrm{P}$ & $\mathrm{S}$ & $\mathrm{Cr}$ & $\mathrm{Ni}$ & $\mathrm{Mo}$ & $\mathrm{Cu}$ & $\mathrm{Nb}$ & $\mathrm{Fe}$ & $\mathrm{W}$ & $\mathrm{V}$ & $\mathrm{N}$ \\
\hline P92 steel & 0.12 & 0.22 & 0.51 & 0.016 & 0.005 & 8.62 & 0.20 & 0.40 & 0.11 & 0.005 & - & 1.79 & 0.20 & - \\
Weld metal & 0.10 & 0.22 & 0.74 & 0.009 & 0.006 & 8.56 & 0.61 & 0.55 & 0.03 & 0.041 & - & 1.72 & 0.198 & 0.047 \\
\hline
\end{tabular}

Table 2. Welding procedure specification of P92 steel

\begin{tabular}{|c|c|c|c|c|c|c|c|c|}
\hline \multirow{2}{*}{$\begin{array}{l}\text { Pass } \\
\text { No. }\end{array}$} & \multirow{2}{*}{$\begin{array}{l}\text { Welding } \\
\text { method }\end{array}$} & \multicolumn{2}{|c|}{ Welding materials } & \multicolumn{2}{|c|}{ Current } & \multirow{2}{*}{$\begin{array}{c}\text { Voltage } \\
(\mathrm{V})\end{array}$} & \multirow{2}{*}{$\begin{array}{c}\text { Travel } \\
\text { speed } \\
\left(\mathrm{mm} \mathrm{s}^{-1}\right)\end{array}$} & \multirow{2}{*}{$\begin{array}{c}\text { Layer } \\
\text { thickness } \\
\quad(\mathrm{mm})\end{array}$} \\
\hline & & Electrode & $\begin{array}{l}\text { Diameter } \\
(\mathrm{mm})\end{array}$ & Polarity & $\begin{array}{c}\text { Ampere } \\
(\mathrm{A})\end{array}$ & & & \\
\hline $1-3$ & GTAW & Thermanit $^{\mathrm{TM}}$ MTS616 & 2.4 & $\mathrm{DC}$ & $80-100$ & $10-12$ & $0.75-1$ & 2 \\
\hline $4-5$ & SMAW & Thermanit $^{\mathrm{TM}}$ MTS616 & 2.5 & $\mathrm{AC}$ & $80-90$ & $20-22$ & $1.67-2.17$ & 2 \\
\hline $6 \sim$ & SMAW & Thermanit $^{\mathrm{TM}}$ MTS616 & 3.2 & $\mathrm{AC}$ & $100-120$ & $20-24$ & $1.67-2.5$ & 2.5 \\
\hline
\end{tabular}

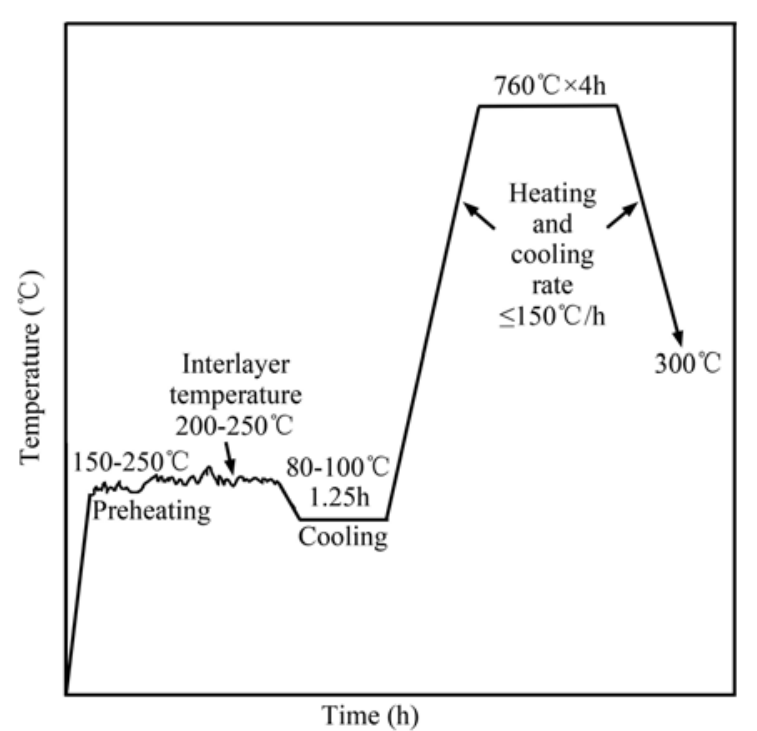

Fig. 1. Heat treatment cycle of the welding process.

weld joint was fabricated using the welding parameters mentioned above. Since the thermal dilatometer equipment is not available which is normally used to the measure $M_{\mathrm{s}}$ and $M_{\mathrm{f}}$, we could not measure the $M_{\mathrm{s}}$ and $M_{\mathrm{f}}$ of the weld metal.

Precipitates were electrolytically extracted from the weld metal using the solution of $36 \mathrm{~g} / \mathrm{LZnCl}_{2}+$ $5 \%(\mathrm{~V} / \mathrm{V}) \mathrm{HCl}+10 \mathrm{~g} / \mathrm{LC}_{6} \mathrm{H}_{8} \mathrm{O}_{7}+\mathrm{CH}_{3} \mathrm{OH}$ (bal.) for characterization. Phase constituent analysis of the precipitates was performed using an X-ray Diffractometer (XRD) with $\mathrm{Cu} \mathrm{K} \alpha$ radiation operating at $40 \mathrm{kV}$ and $100 \mathrm{~mA}$ with a step size of $0.02^{\circ}$, counting time of $1 \mathrm{~s}$, and a scanning angle $(2 \theta)$ ranging from $20^{\circ}$ to $100^{\circ}$. Optical microscopy and scanning electron microscopy (SEM) were used to study the microstructure of the weld metal. Transmission electron microscopy
(TEM) was adopted to examine the microstructure of the precipitates. Standard Charpy impact toughness specimens were fabricated by electro-discharge machining followed by grinding. The impact specimens had dimensions of $10 \mathrm{~mm} \times 10 \mathrm{~mm} \times 55 \mathrm{~mm}$. Charpy test was conducted at room temperature $\left(20^{\circ} \mathrm{C}\right)$. Samples used for the Charpy test were sectioned perpendicular to the girth weld with the $\mathrm{V}$-notch located in the centerline of the weld metal. The average value of three samples was adopted to measure the impact energy of the weld metal. These three samples were distributed evenly along the radial direction of the P92 steel pipe.

\section{Results and discussion}

\subsection{Phase constituent}

Under creep condition with long-term exposure to high temperature, carbides and carbo-nitrides precipitate in the weld metal of P92 steel. After Ostwald ripening, these precipitates will undergo coarsening. Figure 2 shows the XRD results of the electrolytically extracted precipitates. From Fig. 2, it can be seen that MX, $\mathrm{M}_{23} \mathrm{C}_{6}$, and Laves phase precipitated in the weld metal. $\mathrm{M}_{23} \mathrm{C}_{6}$ is a $\mathrm{Cr}$-rich carbide with a face-centred crystal structure. The MX carbonitride has a $\mathrm{NaCl}$ face-centred cubic structure with $\mathrm{M}$ representing $\mathrm{Nb}$ and $\mathrm{V}$ for precipitates in the P92 weld metal. It is well established that the newly fabricated P92 weld metal after heat treatment consists of $\mathrm{MX}, \mathrm{M}_{23} \mathrm{C}_{6}$, and tempered martensite matrix [7]. Thus, the conclusion can be made that Laves phase which is a $\mathrm{Fe}_{2} \mathrm{~W}$ type hexagonal phase consists of the newly formed precipitates. The presence of Laves phase has a significant influence on the toughness of the weld metal which will be explained later. 


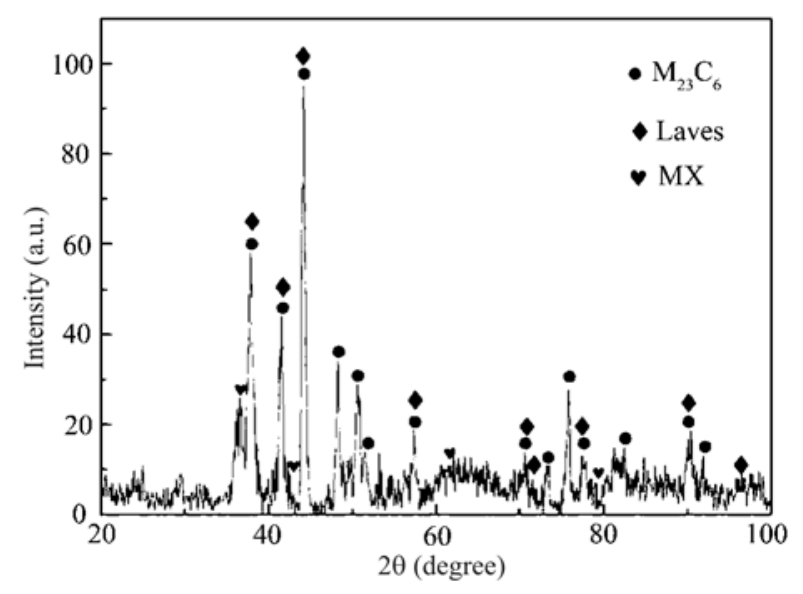

Fig. 2. XRD pattern of the precipitates formed in the weld metal after long-term service.

\subsection{Microstructure}

The microstructure of weld metal in the PWHT state and after long-term service is shown in Fig. 3. Tempered martensite structure was found for both weld metal which comprised of large packets of martensite block and lath. Coarsening of martensitic block and lath of the weld metal after long-term service can be observed due to the occurrence of recovery.

SEM images (Fig. 4) were taken to study the detailed microstructure of P92 weld metal. For the weld metal in the PWHT state, the tempered martensite packet, block and lath were decorated with precipitates of different size and distribution. Precipitates with relatively large size were mostly found on prior austenite grain boundaries and at martensite lath or block boundaries. Some nano-sized particles with a spherical shape formed inside the martensite lath can be found. Due to the high quenching tendency of this steel, cooling in air from austenitizing temperature leads to fully martensitic microstructure. The subsequent tempering of the weld metal below $A_{\mathrm{c} 1}$ results in the formation of precipitates of $\mathrm{MX}$ and Cr-rich $\mathrm{M}_{23} \mathrm{C}_{6}$. Whereas $\mathrm{M}_{23} \mathrm{C}_{6}$ precipitate mainly on grain and subgrain boundaries, the MX carbonitrides are present mainly inside the subgrains [8]. After long-term service, microstructure evolution of the precipitates in terms of amount, shape, and distribution can be found. Significant coarsening of precipitates occurs
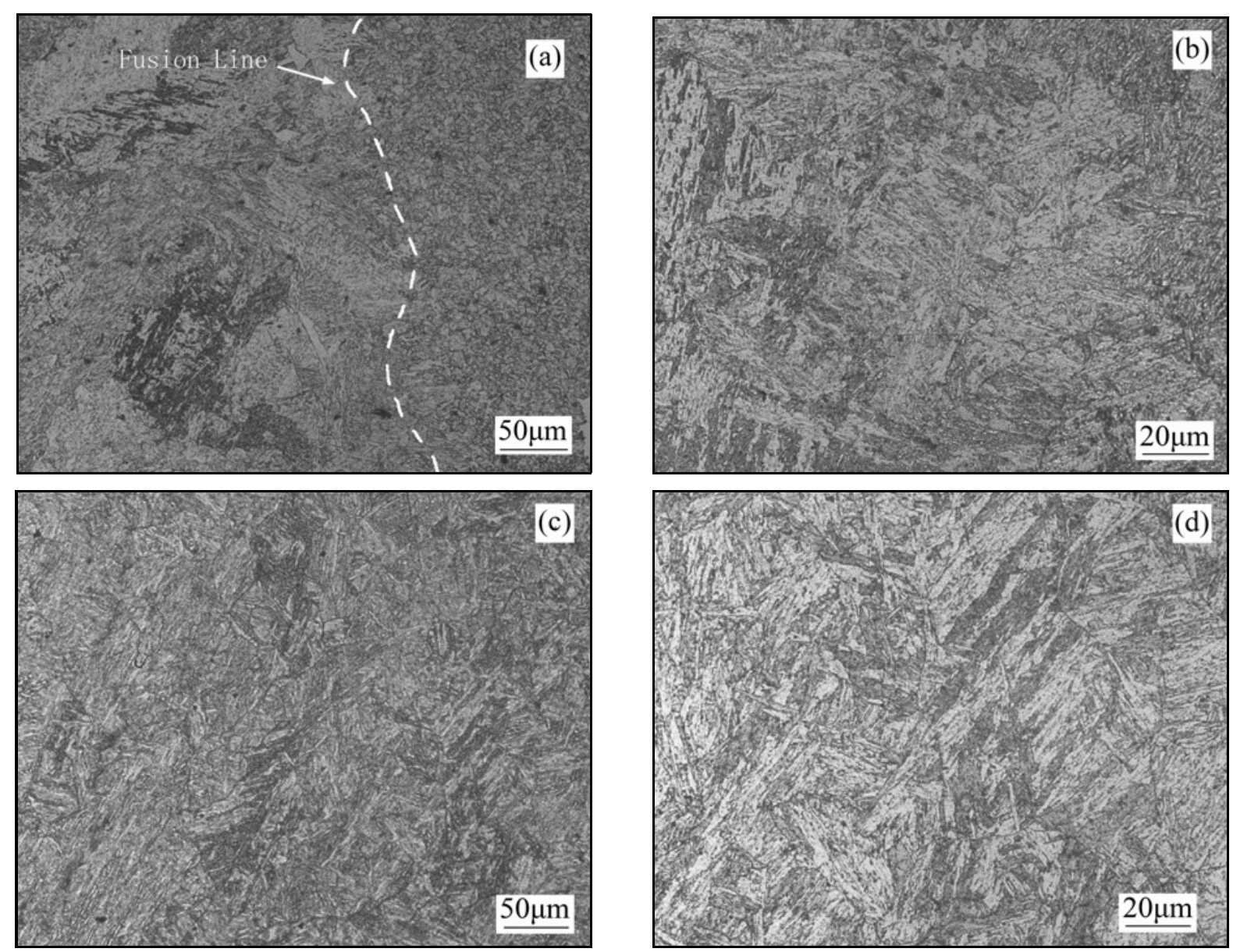

Fig. 3. Optical micrographs of P92 weld metal: (a), (b) PWHT; (c), (d) after long-term service. 

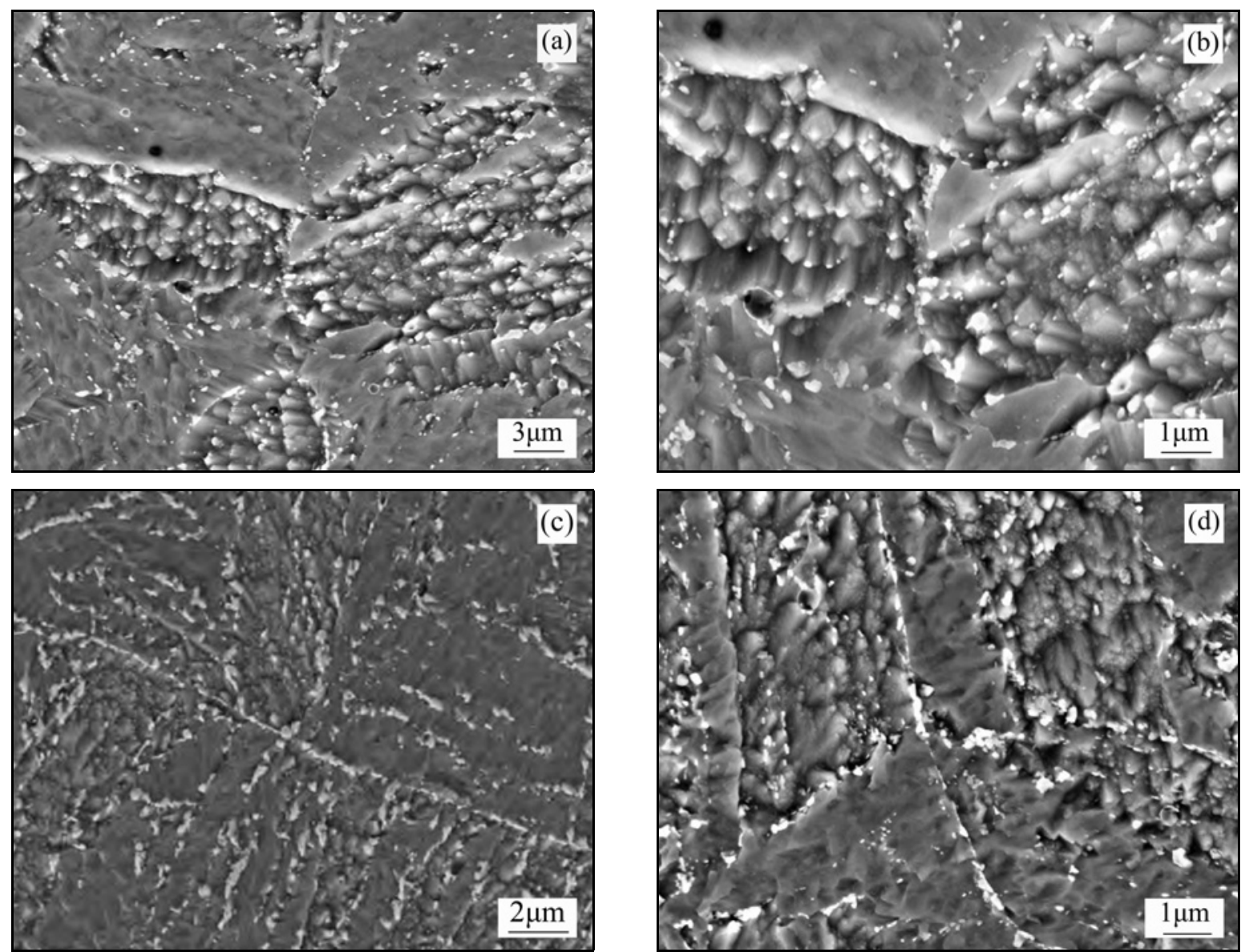

Fig. 4. SEM images of the weld metal in PWHT state and after long-term service: (a), (b) PWHT; (c), (d) after long-term service.
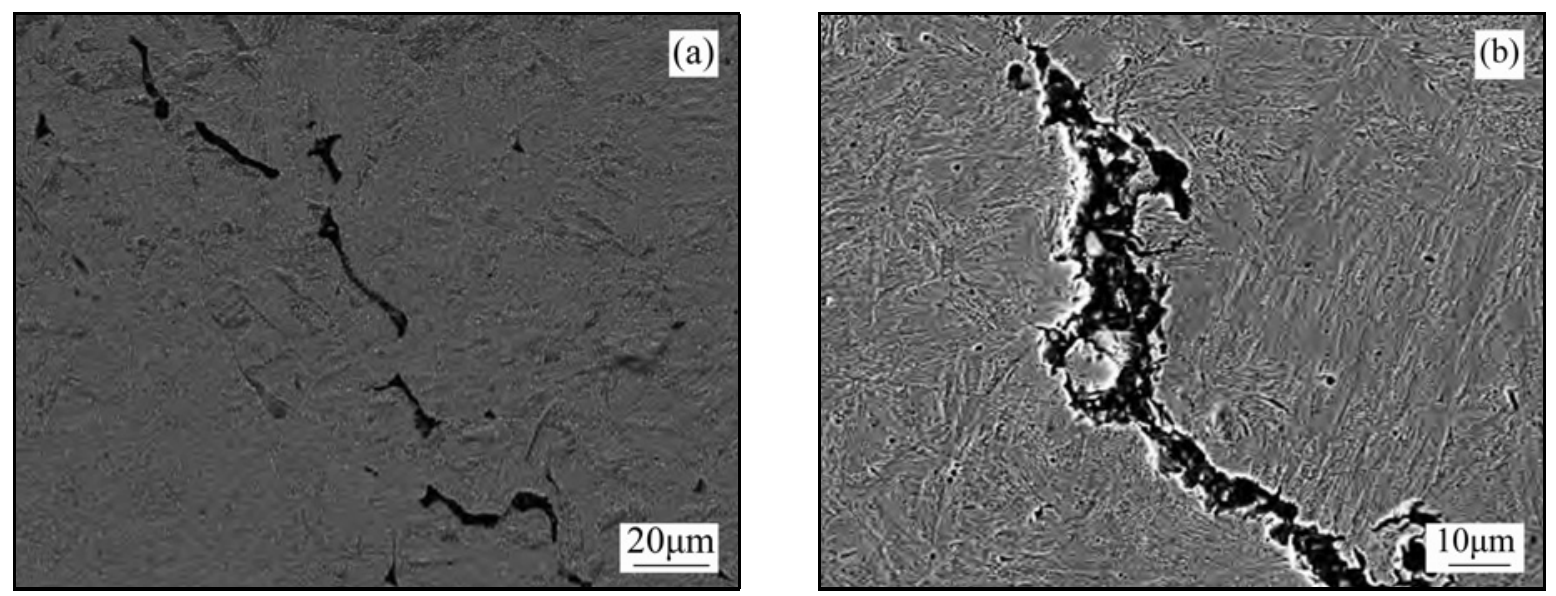

Fig. 5a,b. SEM images of the micro-cracking in the weld metal after long-term service.

along the austenite grain boundaries and martensite block and lath boundaries. These precipitates show the morphology of sphere and block with relatively large size compared with that of the weld metal in PWHT state.

Another phenomenon that should be noticed is the detection of micro-cracking in the weld metal after long-term service (Fig. 5). These cracks show a discontinuous morphology with a length of $20-40 \mu \mathrm{m}$ for each one. These cracks exhibit intragranular morphology, which shows the characteristics of hot cracking. It is postulated that hot cracks formed during the fabrication of weld joint in the power plant. The formation of hot cracks depends on the elements of the weld 

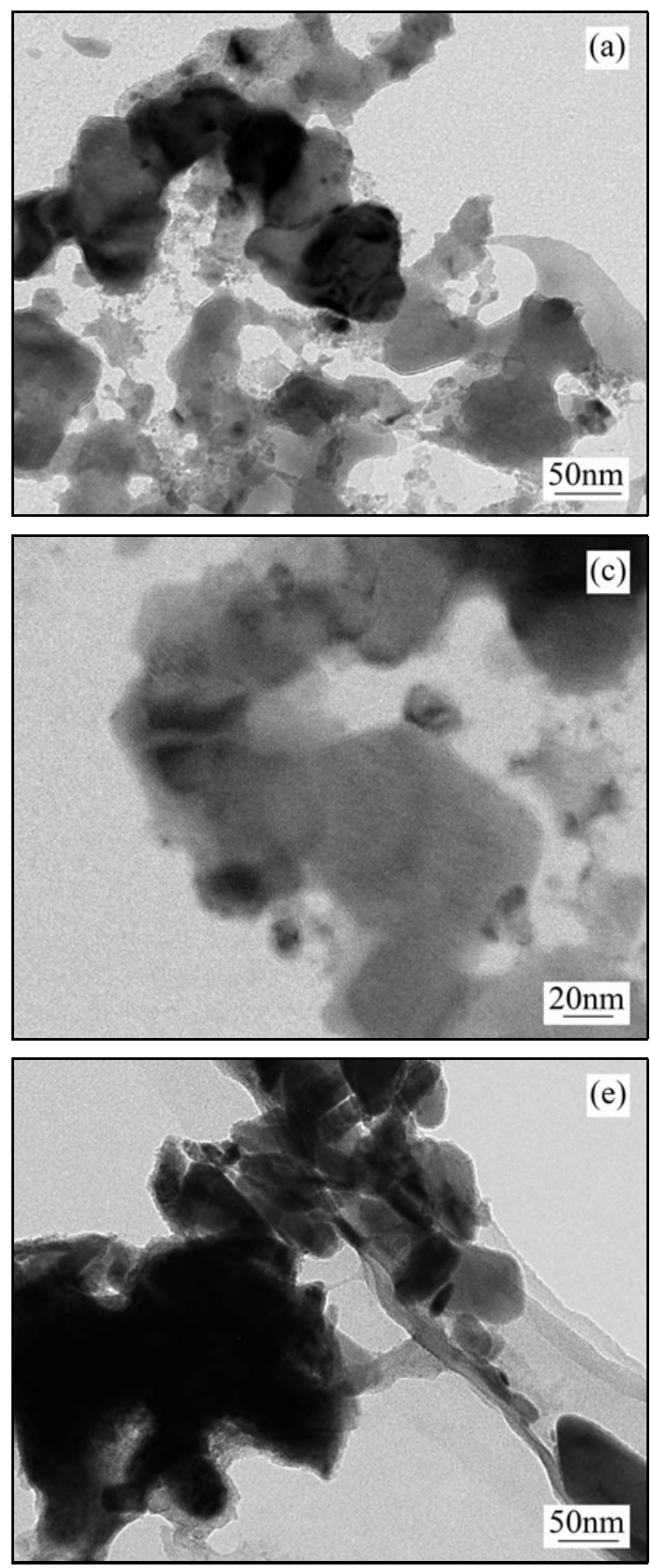
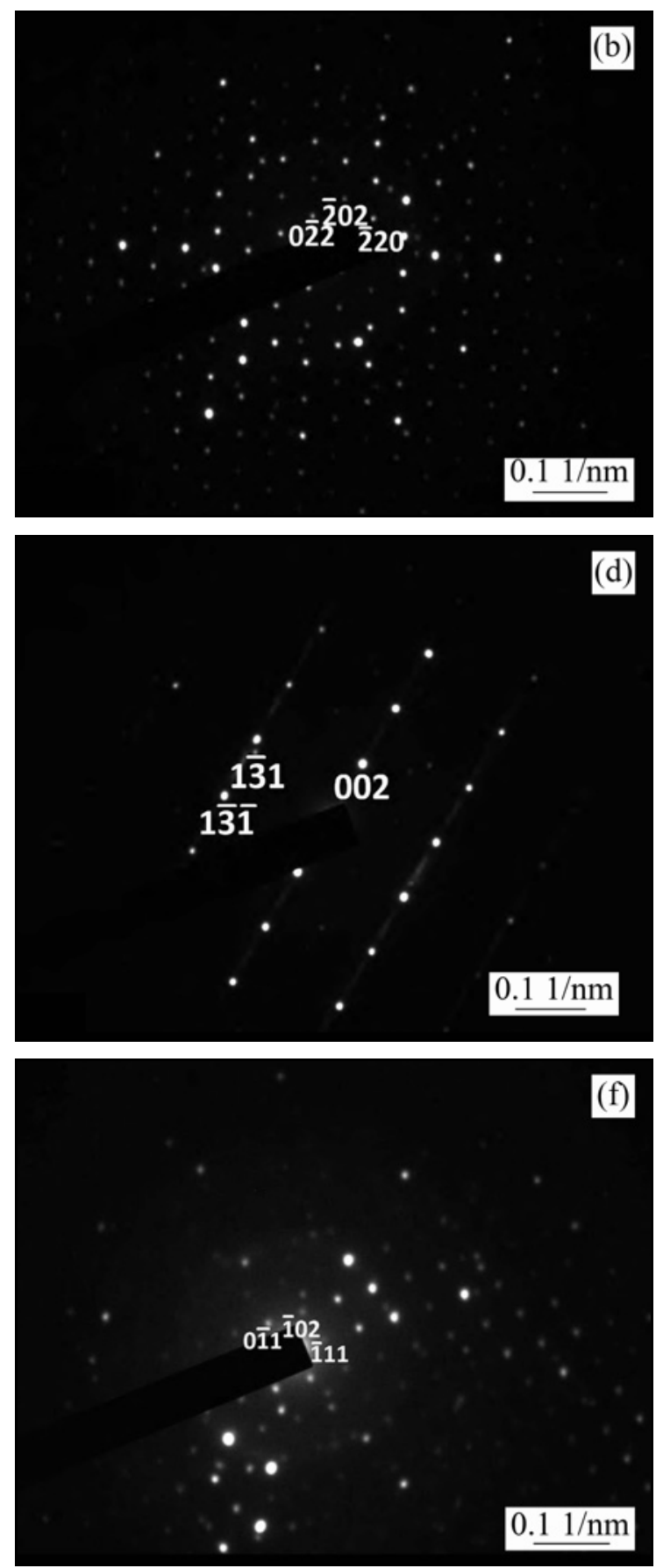

Fig. 6. TEM micrographs of eletrolytically extracted precipitates with their corresponding diffraction pattern: (a), (b) $\mathrm{M}_{23} \mathrm{C}_{6}$ with SADP zone axis of [111]; (c), (d) (Nb,V) (C,N) with SADP zone axis of [310] and (e), (f) Laves phase with SADP zone axis of [211].

and the welding process. However, the nature of these cracks needs further study which is ongoing and will be presented in a further paper.

Electrolytically extracted precipitates were characterized by using TEM, as shown in Fig. 6. TEM reveals the presence of precipitates of $\mathrm{M}_{23} \mathrm{C}_{6}, \mathrm{MX}$, and Laves phase. By combining with the XRD result, a newly formed precipitate in P92 weld metal after long-term service is the Laves phase. The Laves phase shows a blocky morphology with relatively large size. It is an intermetallic phase which significantly influences the mechanical properties.

According to the thermodynamic calculation, ferrite, $\mathrm{M}_{23} \mathrm{C}_{6}$, $\mathrm{MX}$, and Laves phase are equilibrium phases for P92 steel weld metal [9]. It has been found that $\mathrm{M}_{23} \mathrm{C}_{6}$ carbides precipitate mainly at various boundaries, and MX mainly inside the lath, as shown in Figs. 4a,b. However, after long-term service at high 
Table 3. Impact energy values of the weld metal

\begin{tabular}{lcc}
\hline State & Impact energy $(\mathrm{J})$ & Average value $(\mathrm{J})$ \\
\hline PWHT & $47,43,41$ & 43.7 \\
Served for $8000 \mathrm{~h}$ & $8,8,6$ & 7.3 \\
\hline
\end{tabular}
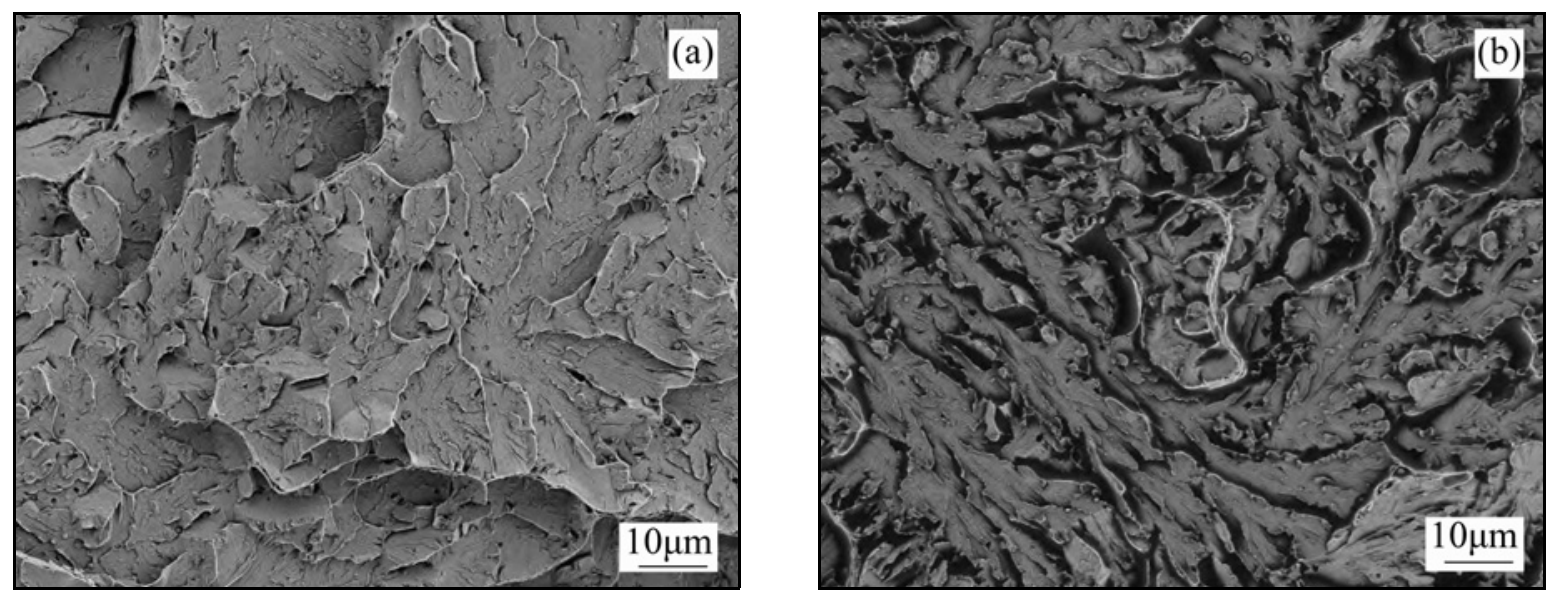

Fig. 7. Fractography of weld metal in PWHT state and after long-term service: (a) PWHT; (b) after long-term service.

temperature, $\mathrm{M}_{23} \mathrm{C}_{6}$ particles grow rapidly, and Ostwald ripening can happen, leading to their relatively large size. Since the equilibrium condition had not been reached yet, Laves phase was not detected in the weld metal in the PWHT state [10]. After longterm service, Laves phase nucleates and grows in the weld metal. EDS analysis shows that the Laves phase is rich in $\mathrm{Cr}, \mathrm{Fe}, \mathrm{W}$, and Mo. Laves phase predominantly nucleates along boundaries of former austenite grains and martensite laths in the vicinity of $\mathrm{M}_{23} \mathrm{C}_{6}$ particles $[10,11]$.

\subsection{Impact toughness}

Charpy impact toughness test was performed for both the newly-fabricated and long-term servicing P92 weld metal (Table 3). A significant drop of impact toughness can be observed for the long-term served P92 weld metal compared with the weld metal in PWHT state. Impact energy reaches $43.7 \mathrm{~J}$ for $\mathrm{P} 92$ weld metal in the PWHT condition. However, after $8000 \mathrm{~h}$ service at $605^{\circ} \mathrm{C}$, impact energy of P92 weld metal decreases to $7.3 \mathrm{~J}$.

Fracture surfaces of P92 weld metal were observed, and the results are shown in Fig. 7. Both of them show typical brittle fracture with no sign of intensive plastic deformation. Nevertheless, slightly higher ridges can be observed for the weld metal in PWHT state. For weld metal, after long-term service, its fracture surface is quite flat with no ridges corresponding to its low impact energy and brittle nature.

The decrease in impact energy can be attributed to the presence of Laves phase and the growing and ripening of $\mathrm{M}_{23} \mathrm{C}_{6}$ in the $\mathrm{P} 92$ weld metal. Due to the large particle growth on the boundaries, particlematrix interphase strength decreases significantly, leading to the reduction in toughness. Compared with $\mathrm{M}_{23} \mathrm{C}_{6}$, Laves phase is more detrimental to the toughness reduction of $\mathrm{P} 92$ weld metal. The brittleness of steels with $\mathrm{W}$ is ascribed to the Laves phase precipitation and its coarsening, generally representing one of the most important processes leading to the degradation of these steels [10-12]. The P92 weld metal exhibited a similar behaviour since Laves phase particles formed at grain boundaries are normally large and dense.

\section{Conclusions}

1. P92 weld metal after long-term service shows a tempered martensite microstructure with an inhomogeneous distribution of precipitates of $\mathrm{MX}, \mathrm{M}_{23} \mathrm{C}_{6}$, and Laves phase. Laves phase is formed during the long-term service at high temperature.

2. Due to the presence of large Laves phase and $\mathrm{M}_{23} \mathrm{C}_{6}$ particles formed at austenite and martensite interface boundaries, P92 weld metal after $8000 \mathrm{~h}$ service at high temperature shows a significant reduction in impact toughness.

\section{Acknowledgement}

This research was supported financially by the Na- 
tional Natural Science Foundation of China (Grant No. 51271099).

\section{References}

[1] Falat, L., Výrostková, A., Homolová, V., Svoboda, M.: Eng. Fail. Anal., 16, 2009, p. 2114. doi:10.1016/j.engfailanal.2009.02.004

[2] Fournier, B., Salvi, M., Dalle, F., De Carlan, Y., Caës, C., Sauzay, M., Pineau, A.: Int. J. Fatigue, 32, 2010, p. 971. doi:10.1016/j.ijfatigue.2009.10.017

[3] Maruyama, K., Armaki, H. G., Chen, R. P., Yoshimi, K., Yoshizawa, M., Igarashi, M.: Int. J. Pres. Ves. Pip., 87, 2010, p. 276. doi:10.1016/j.ijpvp.2010.03.012

[4] Panait, C. G., Bendick, W., Fuchsmann, A., Gourgues-Lorenzon, A. F., Besson, J.: Int. J. Pres. Ves. Pip., 87, 2010, p. 326. doi:10.1016/i.iipvp.2010.03.017

[5] Kim, B., Jeong, C., Lim, B.: Mater. Sci. Eng. A, 483, 2008, p. 544. doi:10.1016/i.msea.2006.12.151
[6] Yuan, L., Tsukamoto, S., Sawada, K., Abe, F.: Metal. Mater. Trans. A, 45, 2014, p. 1306. doi:10.1007/s11661-013-2072-5

[7] Prat, O., Garcia, J., Rojas, D., Sauthoff, G., Inden, G.: Intermetallics, 32, 2013, p. 362. doi:10.1016/j.intermet.2012.08.016

[8] Prat, O., García, J., Rojas, D., Sanhueza, J. P., Camurri, C.: Mater. Chem. Phys., 143, 2014, p. 754. doi:10.1016/i.matchemphys.2013.10.010

[9] Guo, X., Gong, J., Jiang, Y., Rong, D.: Mater. Sci. Eng. A, 564, 2013, p. 199. doi:10.1016/j.msea.2012.10.024

[10] Výrostková, A., Homolová, V., Pecha, J., Svoboda, M.: Mater. Sci. Eng. A, 480, 2008, p. 289. doi:10.1016/j.msea.2007.07.036

[11] Dimmler, G., Weinert, P., Kozeschnik, E., Cerjak, H.: Mater. Charact., 51, 2003, p. 341. doi:10.1016/i.matchar.2004.02.003

[12] Parker, J.: Int. J. Pres. Ves. Pip., 114, 2014, p. 76. doi:10.1016/j.ijpvp.2012.11.004 